\title{
Dynamic load test and lateral load distribution of a modified rigid frame bridge
}

\author{
NING Yu-feng ${ }^{1}$, YANG Qing-cheng ${ }^{1}$, SUN Wei-wei ${ }^{1 *}$, CHEN Shun-chao ${ }^{1}$ \\ ${ }^{1}$ College of Civil Engineering, Southwest Forestry University, Kunming Yunnan 650224
}

\begin{abstract}
In order to evaluate the stress state and working performance of a rigid frame bridge after reconstruction and extension, load test and transverse load distribution were carried out. Static load test is the test of stress at each section of main beam under the action of partial load and medium load. Dynamic load test is used to test the inherent fundamental frequency, damping ratio and impact coefficient of the bridge through pulsation test and sports car test. The results show that the first order vibration of the bridge is mainly transverse vibration from the measured modal parameters, which is consistent with the characteristics of higher pier and greater flexibility. The vibration characteristics of the bridge structure are low frequency and small damping vibration, the value of which belongs to the normal range among similar bridge structures, the overall stiffness of the bridge structure is normal, and the measured impact coefficient during the test of sports car is less than the design impact coefficient, indicating that the dynamic stiffness of the bridge meets the design and specification requirements.
\end{abstract}

\section{Preface}

The dynamic characteristic test of bridge is one of the important indexes to evaluate the bearing capacity and operation condition of bridge. The dynamic load test is used to test the natural vibration characteristic, damping ratio and impact coefficient of bridge, and to study the dynamic load effect of bridge under the action of special load, especially the study of dynamic strain increment and impact coefficient. In order to ensure the normal operation of a modified and extended rigid frame bridge, it is necessary to test the working state of the bridge structure by studying the dynamic load test and lateral load distribution, so as to determine the stress state of the bridge.

At present, more and more scholars have studied the dynamic load test and lateral load distribution of rigid frame box girder Bridges, and some research results have been obtained. For example, Hu Mingzhong et al. 's analysis of sensitivity to design parameters of continuous rigid frame bridge [1]; Li Chun et al. 's study on health monitoring of long-span continuous rigid frame bridge [2]; Li Conghui's analysis on the stability of high-pier largespan continuous rigid frame bridge [3]; He Jia et al. 's research on load test of continuous rigid frame bridge [4]; Research of Wang Hongwei et al on fuzzy comprehensive evaluation method of prestressed concrete continuous rigid frame bridge [5]; Zhu Qinghang's analysis on load test of long-span continuous rigid frame bridge [6]; But at present, there are few literature about the research of load test for the reconstruction and extension of rigid frame bridge in China. Therefore, the research of this topic has application value.

\section{Project Overview}

The bridge is located at $\mathrm{K} 38+783$ of a national highway. The main bridge adopts a three-span prestressed continuous rigid frame system with the span layout of $60 m+100 m+60 m=220 m$. The transverse slope of the bridge deck is bi-directional $2 \%$, and the longitudinal slope of the bridge section is $2.4 \%$ and $2 \%$. The main girder of the bridge is a single-box single-chamber box section, C50 concrete casting, the top width of the box girder is $12.00 \mathrm{~m}$, the bottom width is $6.50 \mathrm{~m}$. The main pier body adopts double-column thin wall pier body, the external outline of the pier body is rectangular, C40 concrete casting. Bored pile foundation is adopted for foundation, U-shaped abutment is adopted for abutment, and 6 bored piles with diameter of $2.00 \mathrm{~m}$ are set under it. The design load of the bridge is highway -I class.

\section{Bridge dynamic load test}

\subsection{Test content}

This dynamic load test mainly includes pulse test and sports car test [10]. The pulsation test uses DH5907N wireless modal tester to test the natural vibration characteristics of the bridge. DH5908 dynamic signal tester is used to collect and analyze dynamic strain in sports car test. The dynamic strain of the superstructure of the bridge was measured under the moving load by using a $400 \mathrm{kN}$ extra-heavy vehicle to cross the bridge at a constant speed along the center line of the carriagway at a

\footnotetext{
* Corresponding author: 429459859@qq.com
} 
speed of $10 \sim 40 \mathrm{~km} / \mathrm{h}$.

\subsection{Arrangement of measuring points and test conditions}

The dynamic strain measuring points are arranged in the middle span L/2 section, and the arrangement of the measuring points is shown in Figure 1.

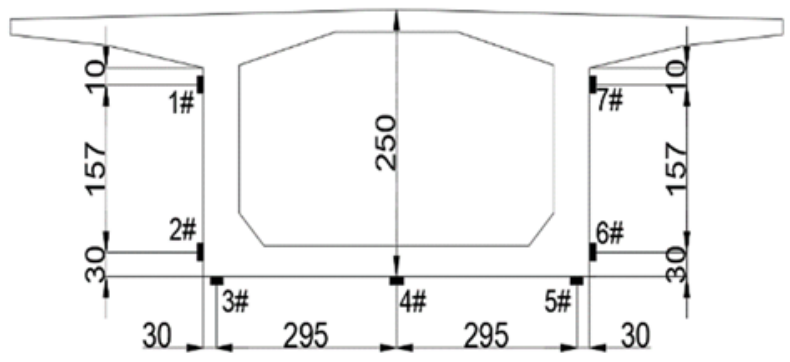

FIG. 1 distribution diagram of dynamic strain measuring points

Table 1 Program table of dynamic load test conditions

\begin{tabular}{|c|c|c|}
\hline $\begin{array}{c}\text { The serial } \\
\text { number }\end{array}$ & $\begin{array}{c}\text { Working } \\
\text { content }\end{array}$ & Test content \\
\hline 1 & $\begin{array}{c}10 \mathrm{~km} / \mathrm{h} \text { barrier- } \\
\text { free sports car }\end{array}$ & $\begin{array}{c}\text { Vibration acceleration, } \\
\text { dynamic strain }\end{array}$ \\
\hline 2 & $\begin{array}{c}20 \mathrm{~km} / \mathrm{h} \text { barrier- } \\
\text { free sports car }\end{array}$ & $\begin{array}{c}\text { Vibration acceleration, } \\
\text { dynamic strain }\end{array}$ \\
\hline 3 & $\begin{array}{c}30 \mathrm{~km} / \mathrm{h} \text { barrier- } \\
\text { free sports car }\end{array}$ & $\begin{array}{c}\text { Vibration acceleration, } \\
\text { dynamic strain }\end{array}$ \\
\hline 4 & $\begin{array}{c}40 \mathrm{~km} / \mathrm{h} \text { barrier- } \\
\text { free sports car }\end{array}$ & $\begin{array}{c}\text { Vibration acceleration, } \\
\text { dynamic strain }\end{array}$ \\
\hline
\end{tabular}

\subsection{Results and analysis of natural vibration characteristics}

Selected cross this bridge is the most unfavorable moment of the cross section test, test load vehicles in without any obstacle, with 1 load car (total weight about $400 \mathrm{kn}$ ) with $10 \mathrm{~km} / \mathrm{h}, 20 \mathrm{~km} / \mathrm{h}, 30 \mathrm{~km} / \mathrm{h}, 40 \mathrm{~km} / \mathrm{h}$ speed past the bridge span structure, use DH5907 dynamic signal collection and analysis of test data test and analysis system, determination of bridge span structure in running vehicle load under the action of dynamic strain. According to the maximum dynamic strain amplitude of bridge vibration, the impact coefficient of bridge span structure under different speed is calculated.

According to the dynamic response signal of the bridge under environmental excitation and the residual vibration signal of the sports car test, the natural vibration characteristics and damping ratio of the bridge can be obtained. The measured basic frequency of the natural vibration of the structure and the theoretical value calculated by the finite element software are shown in Table 2. The calculated and measured modes of vibration of each order of vertical bending theory are shown in Figure 2 9.
Table 2 Pulsating test result

\begin{tabular}{|c|c|c|c|c|}
\hline $\begin{array}{c}\text { Order } \\
\text { number }\end{array}$ & $\begin{array}{c}\text { Theoretical } \\
\text { fundamenta } \\
\text { l frequency } \\
/(\mathbf{H z})\end{array}$ & $\begin{array}{c}\text { Measured } \\
\text { fundamental } \\
\text { frequency } \\
/(\mathbf{H z})\end{array}$ & $\begin{array}{c}\text { Measured } \\
\text { damping } \\
\text { ratio/(\%) }\end{array}$ & $\begin{array}{c}\text { Measured } \\
\text { frequency/ } \\
\text { theoretical } \\
\text { frequency }\end{array}$ \\
\hline 1 & 1.619 & 1.782 & 0.015 & 1.101 \\
\hline 2 & 2.605 & 3.076 & 0.010 & 1.181 \\
\hline 3 & 3.143 & 3.883 & 0.011 & 1.220 \\
\hline 4 & 4.513 & 5.273 & 0.010 & 1.168 \\
\hline
\end{tabular}

As can be seen from Table 2, the ratios of the measured frequency and theoretical frequency of the first four orders of vertical vibration of the bridge are: 1.101, 1.181, 1.220 and 1.168 respectively, which all meet the requirements of $\geq 0.90$ in literature [7]. The corresponding measured damping ratios are $0.015,0.010,0.011$ and 0.010 respectively, which are all within a reasonable range, indicating that the dynamic stiffness of the bridge meets the design and specification requirements.

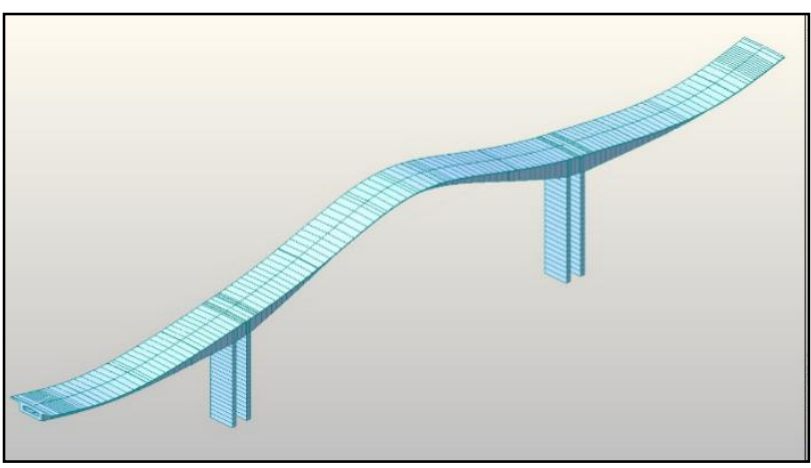

FIG. 2 Diagram of first-order vertical theoretical mode of vibration $(\mathrm{F} 1=1.619 \mathrm{~Hz})$

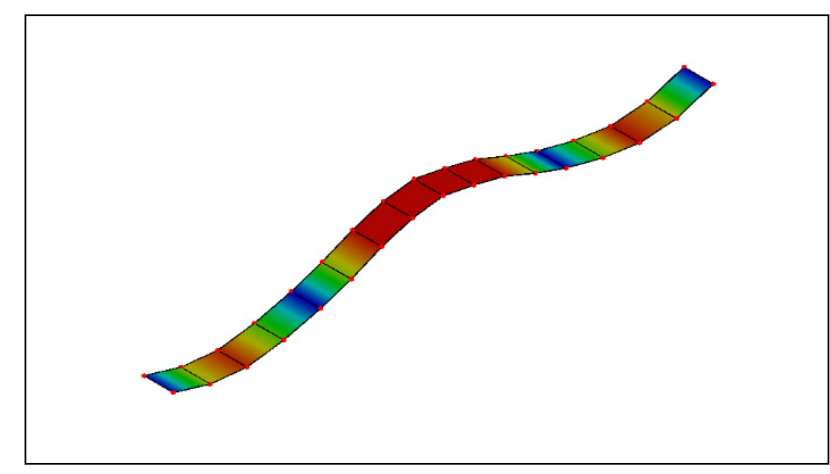

FIG. 3 Measured values of first-order vertical frequency (F1 $=1.782 \mathrm{~Hz}$ ) 


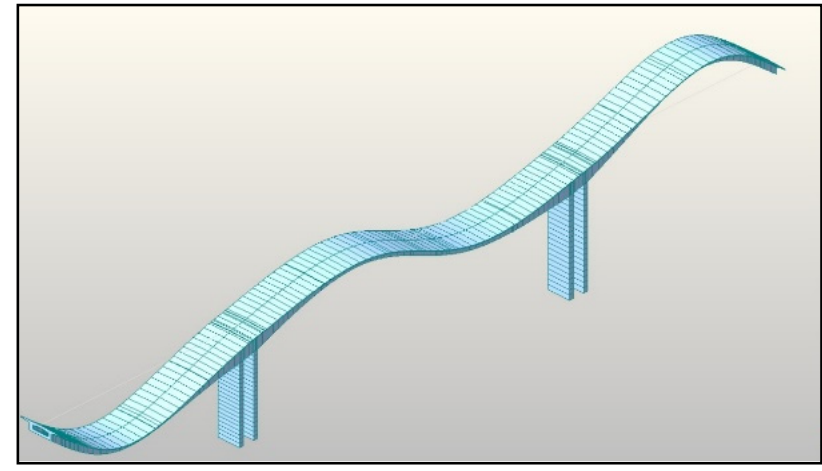

FIG. 4 Second-order vertical theoretical mode diagram (F2 $=2.606 \mathrm{~Hz}$ )

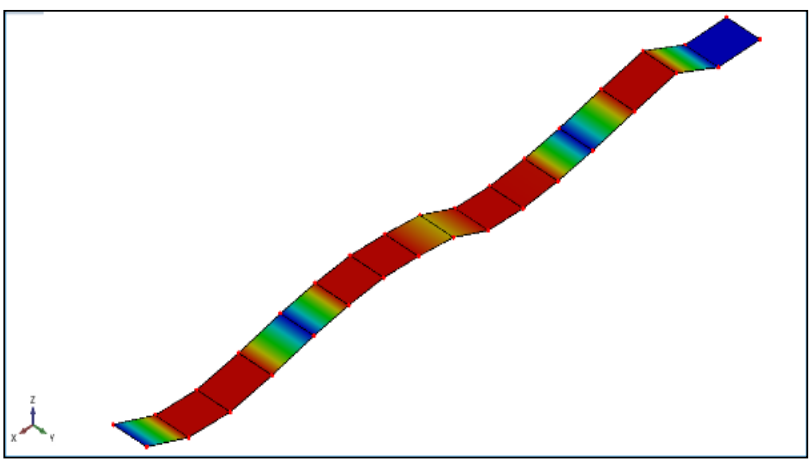

FIG. 5 Measured value of second-order vertical frequency (F2 $=3.076 \mathrm{~Hz})$

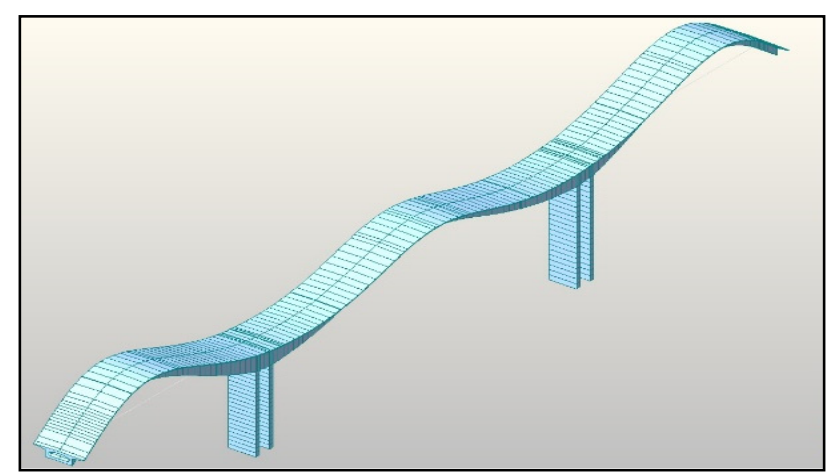

FIG. 6 Diagram of third-order vertical theoretical mode of vibration $(\mathrm{F} 3=3.143 \mathrm{~Hz})$

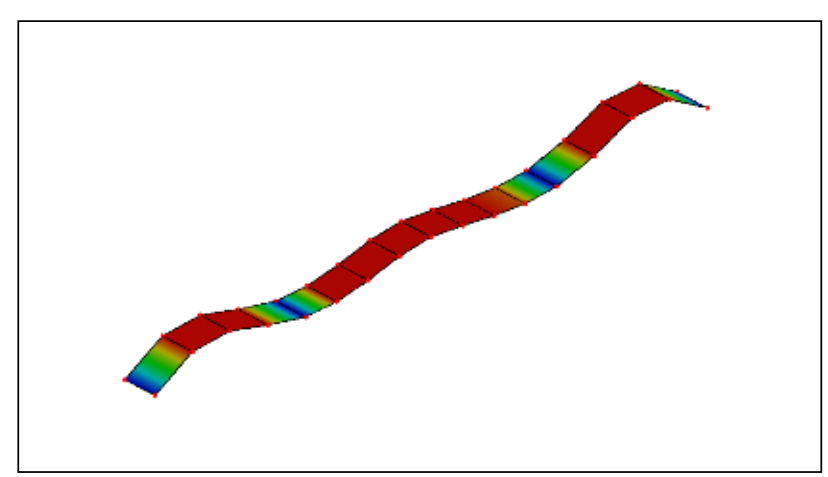

FIG. 7 Measured value of third-order vertical frequency (F3 $=3.833 \mathrm{~Hz}$ )

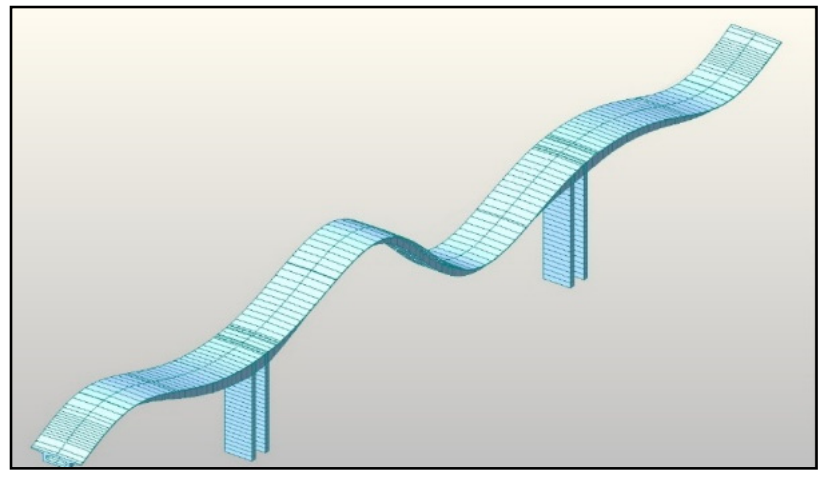

FIG. 8 Fourth-order vertical theoretical mode diagram (F4 $=4.513 \mathrm{~Hz})$

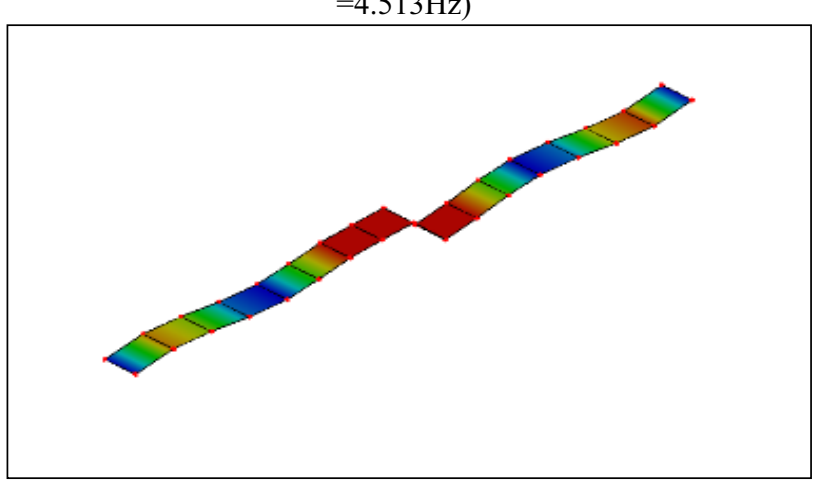

FIG. 9 Measured value of fourth-order vertical frequency (F4 $=5.273 \mathrm{~Hz}$ )

\subsection{Impact coefficient results and analysis}

According to the theoretical calculation of fundamental frequency, the calculated impact coefficient of the test bridge is 0.07 , and the measured dynamic increment coefficient is shown in Table 3.

Table 3 Table of impact coefficients of Bridges at different speeds

\begin{tabular}{|c|c|c|c|c|}
\hline $\begin{array}{c}\text { Test } \\
\text { section }\end{array}$ & $\begin{array}{c}\text { Sports } \\
\text { car } \\
\text { number }\end{array}$ & Speed & $\begin{array}{l}\text { The test } \\
\text { content }\end{array}$ & $\begin{array}{c}\text { Impact } \\
\text { coefficient }\end{array}$ \\
\hline \multirow{4}{*}{$\begin{array}{c}2 \# \\
\text { JM3 }\end{array}$} & \multirow{4}{*}{1} & $10 \mathrm{~km} / \mathrm{h}$ & \multirow{4}{*}{$\begin{array}{c}\text { Dynamic } \\
\text { strain } \\
(\mu \varepsilon)\end{array}$} & 1.019 \\
\hline & & $20 \mathrm{~km} / \mathrm{h}$ & & 1.033 \\
\hline & & $30 \mathrm{~km} / \mathrm{h}$ & & 1.054 \\
\hline & & $40 \mathrm{~km} / \mathrm{h}$ & & 1.076 \\
\hline
\end{tabular}

\section{Conclusion}

(1) The ratio of the measured frequency and theoretical frequency of the first four orders of vertical vibration of the bridge is $1.101,1.181,1.220$ and 1.168 respectively, which meets the requirement of $\geq 0.90$ in literature [7]. The corresponding measured damping ratios are $0.015,0.010$, 0.011 and 0.010 respectively, which are within a reasonable range, indicating that the dynamic stiffness of the bridge meets the design and specification requirements. 
(2) The maximum dynamic coefficient of the bridge sports car test is 1.076 , and the corresponding dynamic strain increment coefficient is 0.076 , less than the design impact coefficient (0.07); Since this dynamic load test uses a single vehicle, the dynamic loading efficiency is low. In the actual multi-vehicle operation of the bridge, the impact coefficient is generally lower than that of a single vehicle due to the mutual cancellation. To sum up, it shows that the bridge deck is in good running condition.

\section{Reference}

1. Hu Mingzhong, Ren Ruixue. Sensitivity Analysis of design parameters of $220 \mathrm{M}$ main-span continuous rigid frame bridge $[\mathrm{J}]$. Highways and Motorways, 2020

2. Li Chun, Chen Chao, XIA Hongda, Yang Xiaoyan. Health monitoring system design for long-span continuous Rigid frame bridge $[\mathrm{J}]$. Sichuan architecture, 2020,40 (5)

3. Li Conghui. Stability analysis of high-pier long-span Continuous Rigid frame bridge [J]. Sichuan Cement,2020

4. He Jia, Ran Binbing, Liang Bo, WANG Bing. Load test of a continuous rigid frame bridge [J]. Sinoforeign highway, 2020,40 (5)

5. Wang Hongwei, XIE Kaizhong. Research on fuzzy comprehensive Evaluation method of prestressed concrete continuous rigid frame Bridge $[\mathrm{J}]$. Journal of hebei university of engineering,2020,37(3)

6. Zhu qing-hang. Load test scheme analysis of longspan continuous rigid frame bridge $[\mathrm{J}]$. Shangdong communications technology, 2020,04

7. Ministry of Transport of the People's Republic of China,Specification for inspection and evaluation of load-bearing capacity of highway bridges: JTG/TJ212011 [S] 